University of Nebraska - Lincoln

DigitalCommons@University of Nebraska - Lincoln

3-20-2003

\title{
The adsorption of orthocarborane on cobalt
}

\author{
L. Bernard \\ University of Nebraska-Lincoln
}

A. N. Caruso

University of Nebraska-Lincoln, carusoan@umkc.edu

Bo Xu

University of Nebraska-Lincoln

Bernard Doudin

University of Nebraska-Lincoln, bernard.doudin@ipcms.unistra.fr

Peter A. Dowben

University of Nebraska-Lincoln, pdowben@unl.edu

Follow this and additional works at: https://digitalcommons.unl.edu/physicsdowben

Part of the Physics Commons

Bernard, L.; Caruso, A. N.; Xu, Bo; Doudin, Bernard; and Dowben, Peter A., "The adsorption of orthocarborane on cobalt" (2003). Peter Dowben Publications. 178.

https://digitalcommons.unl.edu/physicsdowben/178

This Article is brought to you for free and open access by the Research Papers in Physics and Astronomy at DigitalCommons@University of Nebraska - Lincoln. It has been accepted for inclusion in Peter Dowben Publications by an authorized administrator of DigitalCommons@University of Nebraska - Lincoln. 
Published in Thin Solid Films 428:1-2 (March 20, 2003), pp. 253-256; in Proceedings of Symposium J on Growth and Evolution of Ultrathin Films: Surface and Interface Geometric and Electronic Structure, of the E-MRS Spring Conference. doi:10.1016/S0040-6090(02)01283-X Copyright (C) 2002 Elsevier Science B.V. Used by permission.

Published online April 11, 2003.

\title{
The adsorption of orthocarborane on cobalt
}

\author{
L. Bernard ${ }^{1,2}$, A. N. Caruso ${ }^{1}$, Bo Xu${ }^{1}$, B. Doudin ${ }^{1}$, and P. A. Dowben ${ }^{1 *}$ \\ ${ }^{1}$ Department of Physics and Astronomy and the Center for Materials Research and Analysis, Behlen Laboratory of Physics, \\ University of Nebraska-Lincoln, Lincoln, NE 68588-0111, USA \\ ${ }^{2}$ Department of Physics, École Polytechnique Fédérale de Lausanne, CH-1015, Lausanne, Switzerland \\ * Corresponding author.
}

\begin{abstract}
The adsorption of closo-1,2 dicarbadodecaborane (orthocarborane) on evaporated cobalt thin films has been investigated by combined photoemission and inverse photoemission studies. The adsorption of these icosahedral molecules does not strongly perturb the electronic structure of the underlying cobalt. As was previously observed with adsorption on $\mathrm{Cu}(100)$, electron induced decomposition of adsorbed orthocarborane decreases the HOMO-LUMO gap. The X-ray photoemission spectra before and after orthocarborane adsorption confirm that the interface with cobalt is abrupt. These results suggest that chemical vapor deposition, via the decomposition of orthocarborane, may be an effective method for fabricating dielectric barrier layers, without utilizing oxides. This is of interest for spin electronics applications.
\end{abstract}

Keywords: cobalt, adsorption, electron spectroscopy, tunnel junction barriers, boron carbide

Electric transport in ferromagnetic-insulating-ferromagnetic (FM-I-FM) systems has attracted much attention since 1995 $[1,2]$. If the insulating layer is thin enough $(<2 \mathrm{~nm})$ the electron tunneling probability becomes significant. Changes in the resistance of typically $20 \%$, as a function of the applied field, have been observed in magnetic tunnel junctions, though values as high as $450 \%$ are known. Most insulating barriers in FM-I-FM systems are oxides, with the $\mathrm{Al}_{2} \mathrm{O}_{3}$ being the most extensively investigated. Because metals in contact with the oxide barrier can undergo oxidation at the interface [3-5], non-oxide insulating barrier layers have been proposed. The experimental band mapping effort of Osterwalder's group $[6,7]$ has provided evidence of changes in the spin-dependent Fermi surface(s) when hexagonal boron nitride (h-BN) overlayers are deposited on $\mathrm{Ni}(111)$, and the magnetic surface states appear to be enhanced by the overlayer. This suggests that boron based barrier layers may be less likely than many other materials to suppress the interface magnetization: key to a good tunnel junction [8, 9]. Borane and carborane cluster compounds have now been used as source compounds for the chemical vapor deposition
(CVD) of a wide variety of thin film materials including variable band gap boron carbide thin film semiconductors [10-13]. Boron-carbide devices have now been fabricated using orthocarborane (closo-1,2-dicarbadodecaborane) as the source material [13-18], schematically shown as an inset in Figure 1. In orthocarborane, $\mathrm{C}_{2} \mathrm{~B}_{10} \mathrm{H}_{12}$, the two carbon atoms occupy the adjacent 1,2 positions of the icosahedral cage and the 10 boron atoms occupy the remainder, with each atom "dressed" by a hydrogen.

To begin to assess the efficacy of boron carbide grown by CVD as a possible insulating barrier for "spin-electronics" it is important to establish that there are few chemical reactions at the ferromagnet/orthocarborane interface, including interdiffusion, and that the electronic structure of the underlying ferromagnet is left largely unperturbed with adsorption and decomposition. Unfortunately, surface science studies of the adsorption and decomposition of orthocarborane have been limited, thus far, to adsorption on $\mathrm{Cu}\left(\begin{array}{lll}1 & 0 & 0\end{array}\right)$ [19-23] and $\operatorname{Si}\left(\begin{array}{lll}1 & 1 & 1\end{array}\right)$ [24]. In this study, we observe molecular orthocarborane adsorption on cobalt thin films, the first such study of a carborane molecule on a ferromagnet. 


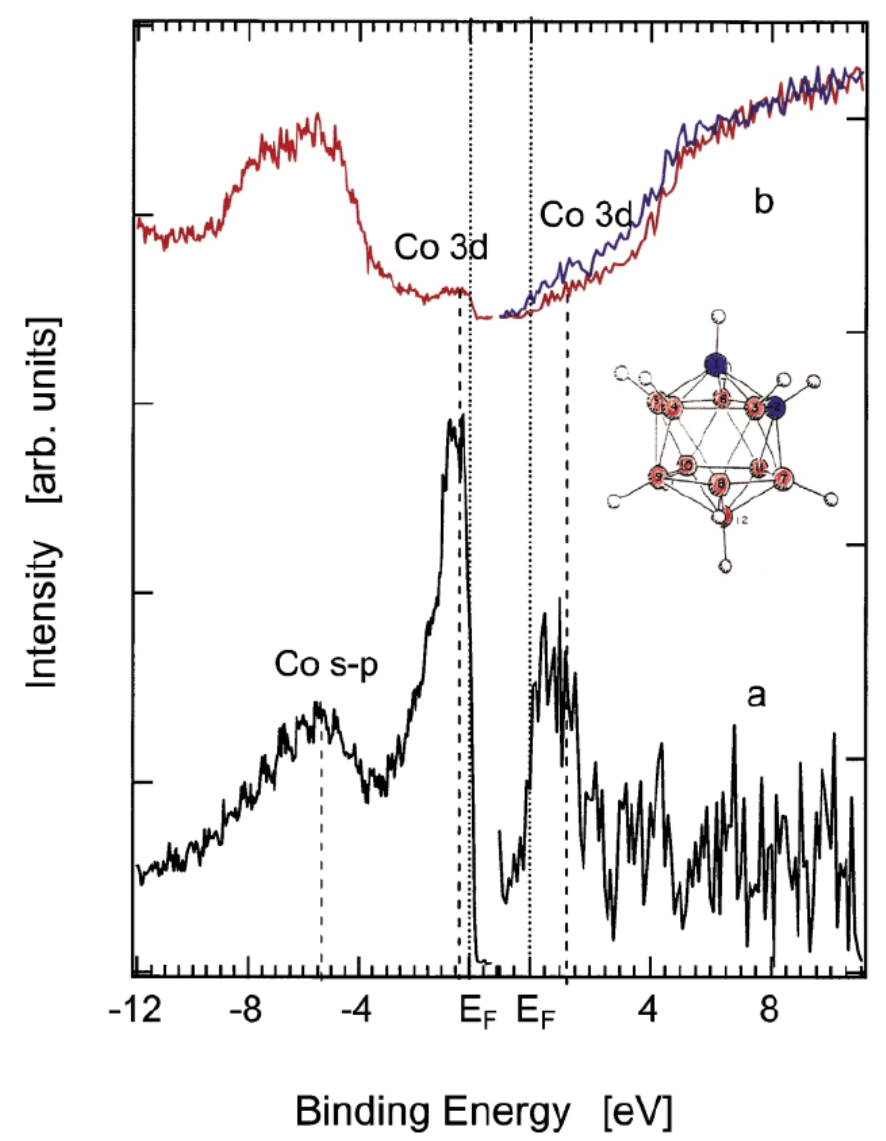

Figure 1. Combined photoemission and inverse photoemission are shown for a cobalt film (A) and following the deposition of an orthocarborane overlayer (B) $12 \AA$ thick (three to four molecules thick). The inset on the right schematically indicates the closo-1,2dicarbadodecaborane with the carbon atoms in the 1,2 positions indicated by blue and the boron indicated by red. Decomposition (see text) of the orthocarborane leads to a shift of the conduction (and valence) band edge as indicated by the inverse photoemission (photoemission) spectra following adsorption (red) and following decomposition (blue).

The cobalt thin film substrates were prepared by vacuum deposition on Au-coated $(1000 \AA)$ silicon substrates, in a preparation chamber vacuum continuous with the spectrometer vacuum system. The He I $(21.2 \mathrm{eV})$ ultraviolet photoemission, angle-resolved inverse photoemission, and XPS were undertaken in a single UHV chamber [22, 23]. The Fermi level was determined from a tantalum foil in intimate contact with the sample substrate, and the gold substrate. A new cobalt substrate surface was prepared prior to each run by thermal evaporation. The purity of the orthocarborane compound was greater than $98 \%$ and a detailed description for the preparation of the orthocarborane has been described elsewhere [25].

Following the evaporation of a clean thick cobalt film on gold, the characteristic occupied and unoccupied $3 \mathrm{~d}$ bands dominate the region near the Fermi level in photoemission and inverse photoemission respectively, as seen in Figure 1 (the photoemission and inverse photoemission spectra marked (a)). This is both predicted [26] and commonly observed in other photoemission [27, 28] and inverse photoemission [29] studies of cobalt.

The adsorption of orthocarborane at $150 \mathrm{~K}$ results in the diminution of the cobalt d-bands and the growth of the characteristic levels representative of the molecular orbitals of orthocarborane [19, 22]. Because the highest occupied (HOMO) to lowest unoccupied (LUMO) molecular orbital gap of adsorbed orthocarborane is so large (9-10 eV in experiment and $11 \mathrm{eV}$ in theory [22]), the cobalt $3 \mathrm{~d}$ bands can still be observed through a thin film of adsorbed orthocarborane $12 \AA$ thick, determined as discussed later.

The residual signal from the underlying cobalt $3 \mathrm{~d}$ bands, in both photoemission and inverse photoemission, are not significantly perturbed by orthocarborane adsorption as seen in the spectra (b) in Figure 1. This is consistent with the XPS measurements: for the clean cobalt film the $2 \mathrm{p}_{3 / 2}$ and $2 \mathrm{p}_{1 / 2}$
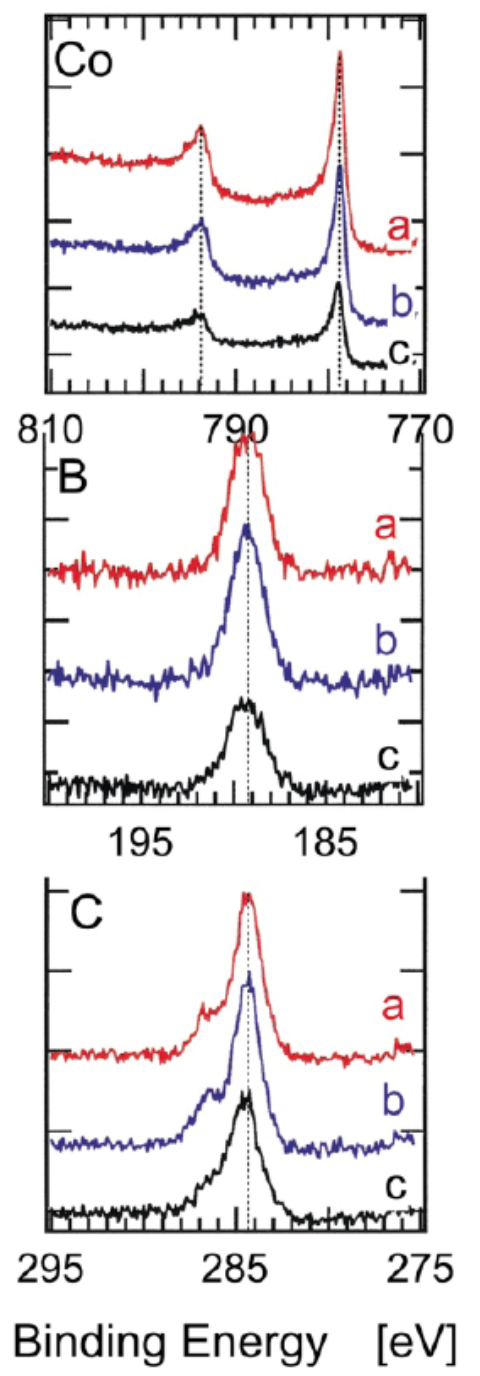

Figure 2. The XPS core levels and respective ratios are plotted for a cobalt film after orthocarborane adsorption at $150 \mathrm{~K}$. The X-ray photoemission spectra for the cobalt $2 \mathrm{p}$, boron $1 \mathrm{~s}$, and carbon 1 s core levels are shown on the left, for normal emission in red, i.e. spectra labeled (A), $30^{\circ}$ off normal emission in blue, i.e. spectra labeled (B), and $60^{\circ}$ off normal emission in black, i.e. spectra labeled (C). 
binding energies of $778.4 \pm 0.1$ and $793.4 \pm 0.2 \mathrm{eV}$ are close to the accepted values [30, 31]. It is known that the icosahedral cage does bind with carbons toward the metal surface for the first molecular monolayer of orthocarborane adsorption on $\mathrm{Cu}\left(\begin{array}{lll}1 & 0 & 0\end{array}\right)$ [19] and we have little reason to doubt that the adsorption of orthocarborane on cobalt would be much different. The shift of these core level binding energies to the higher binding energies of $779.0 \pm 0.1$ and $794 \pm 0.2 \mathrm{eV}$, nonetheless, is closer to the shift expected for the surface to bulk core level shift of cobalt or cobalt bonded in a ligand field, rather than formation of a carbide [31].

Generally, with changing emission angle, the main core level XPS lines do not shift in binding energy, as seen in Figure 2 for the cobalt $2 p$, and boron 1 s core levels. The exception is the carbon 1s XPS spectra which have a satellite line $\left(\mathrm{C}_{\mathrm{s}}\right)$ at $286.5 \pm 0.3 \mathrm{eV}$ binding energy that is greater in intensity for normal emission (a) and diminishes in intensity with $30^{\circ}$ off normal emission (b) and diminishes further still at $60^{\circ}$ off normal emission (c) relative to the main carbon $1 \mathrm{~s}$ peak $\left(C_{p}\right)$ (Figure 2). This is summarized in Figure 3c. In the first orthocarborane layer, the icosahedral cage bonds with the carbons directly down toward the cobalt surface (or directly away from the surface), leading to a shift in the core level due to either deprotonation at the icosahedral carbon to cobalt interface [18] or screened and unscreened final states. If such effects occur at the cobalt interface, then they will be strongest at normal emission where the effective probing depth is deeper than at $60^{\circ}$ off normal emission.

In spite of this likely preferential orientation of the orthocarborane in the first molecular layer, the boron to carbon ratio remains relatively constant with emission angle, as plotted in Figure 3a, indicating that the molecular film is a result of associative adsorption and the $\mathrm{B}_{5} \mathrm{C}$ ratio is preserved. The small diminution of the $\mathrm{B} / \mathrm{C}$ ratio is readily understood, if, in the outermost orthocarborane molecules, there also exists a preferential orientation. If the "outer" orthocarborane molecules are placed with carbon atoms in the icosahedral 1,2 positions oriented outwards toward the surface/vacuum interface, then a small decrease in the $\mathrm{B} / \mathrm{C}$ ratio is to be expected at the largest emission angles, consistent with the observed measurements.

From the ratio of the boron and carbon signals to the cobalt core level signal (normalized for cross-section and analyzer transmission function), as a function of emission angle, we estimate the orthocarborane film thickness to be approximately $10-12 \AA$. This thickness is obtained by fitting the normalized XPS ratio values to the functional:

$$
F(\theta)=\frac{\lambda_{\mathrm{B}_{5} \mathrm{C}}}{\lambda_{\mathrm{Co}}} \frac{\exp \left(-d / \lambda_{\mathrm{B}_{5} \mathrm{C}} \cos (\theta)\right)-1}{\exp \left(-d / \lambda_{\mathrm{Co}} \cos (\theta)\right)}
$$

where $\theta$ is the emission angle (with respect to the surface normal) and $d$ is the film thickness. This fitting has been undertaken in several different ways with little variation in the result, and one such fit is shown in the plotted ratio of $\mathrm{B}_{5} \mathrm{C} / \mathrm{Co}$ in Figure 3b.

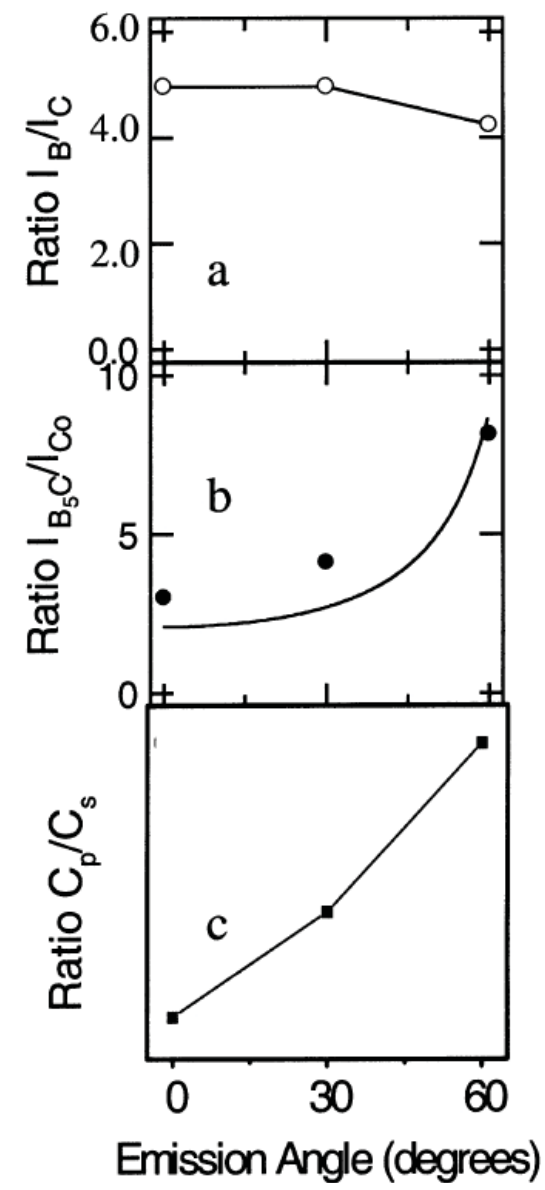

Figure 3. The X-ray photoemission intensity ratios of boron to carbon (A) boron plus carbon to cobalt intensity ratios (B) and the $\mathrm{C}$ 1s satellite line $\left(\mathrm{C}_{\mathrm{s}}\right)$ at $286.5 \pm 0.3 \mathrm{eV}$ binding energy to the $\mathrm{C} 1 \mathrm{~s}$ principal line $\left(\mathrm{C}_{\mathrm{p}}\right)$ at $284.3 \pm 0.2 \mathrm{eV}$ binding energy $(\mathrm{C})$ have been plotted as a function of emission angle. For the ratio of boron plus carbon to cobalt, the XPS intensity ratio has been model based on an overlayer thickness of $12 \AA$ thick, and the fit to the data is shown.

Aside from the preferential orientation of the icosahedra at the cobalt interface, the absence of core level shifts of cobalt and boron, as plotted for different emission angles in Figure 2 , confirm that the interface, between cobalt and the adsorbed orthocarborane, is abrupt. The assessment obtained from the combined photoemission and inverse photoemission is in agreement with this inference from the angle-resolved XPS. Furthermore, we are able to conclude that strong chemical reactions that result in carbide formation or cobalt dissolution in the molecular overlayer do not occur.

As with orthocarborane adsorption on $\mathrm{Cu}\left(\begin{array}{lll}1 & 0 & 0\end{array}\right)[13,20]$, prolonged exposure to incident radiation, secondary electrons or low energy electrons, leads to the decomposition of the orthocarborane and formation of the semiconducting/insulating dielectric polytype of boron carbide. After a brief exposure to the $200 \mathrm{eV}$ electrons for $600 \mathrm{~A} \mathrm{~s} / \mathrm{cm}^{2}$, a shift of the conduction band edge (the lowest unoccupied molecular orbital) is observed in the inverse photoemission in Figure 1 (the shift from the red to the blue). With continued electron beam exposure, the 
shifts continue as was observed at the valence band edge for orthocarborane on $\mathrm{Cu}\left(\begin{array}{lll}1 & 0 & 0\end{array}\right)$ [20]. It is clear that the correct dielectric polytype of boron carbide can be so formed on the cobalt. As the core level binding energies do not significantly shift with orthocarborane adsorption, the interface remains largely "intact" as expected from a decomposition process that is largely a deprotonation of the icosahedral cage (loss of exopolyhedral hydrogen).

While very similar to adsorption studies of orthocarborane carried out on copper surfaces, the results here suggest that orthocarborane adsorption and decomposition is a route to the fabrication of dielectric barrier layer for a high magnetoresistance device.

\section{Acknowledgements}

The support of the Office of Naval Research, and the Nebraska Research Initiative are gratefully acknowledged.

\section{References}

1. J.S. Moodera, L.R. Kinder, T.M. Wong and R. Meservey. Phys. Rev. Lett. 74 (1996), p. 3273.

2. T. Miyazaki and N. Tezuda. J. Magn. Magn. Mater. 139 (1995), p. L231.

3. T.J. Regan, H. Ohldag, C. Stamm, F. Nolting, J. Lüning, J. Stöhr, R.L. White, Phys. Rev. B 64 (2001) art. no. 214422

4. H. Ohldag, A. Scholl, F. Nolting, S. Anders, F.U. Hillebrecht and J. Stöhr. Phys. Rev. Lett. 86 (2001), pp. 2878-2881.

5. R. Cheng, C.N. Borca, N. Pilet, B. Xu, L. Yuan, B. Doudin, S.H. Liou and P.A. Dowben. Appl. Phys. Lett. 81 (2002), pp. 21092111.

6. T. Greber, W. Auwärter and J. Ostwalder. In: J.L. Moran-Lopez, Editor, The Physics of Low Dimensional Systems, Plenum, New York (2000).

7. J. Osterwalder. J. Electron Spectrosc. Rel. Phenom. 117-118 (2001), p. 71.

8. I.I. Mazin. Phys. Rev. Lett. 83 (1999), p. 1427.

9. J. Mathon. Phys. Rev. B 56 (1997), p. 11810.

10. S. Lee, J. Mazurowski, G. Ramseyer and P.A. Dowben. J. Appl. Phys. 72 (1992), p. 4925.

11. S. Lee and P.A. Dowben. Appl. Phys. A 58 (1994), p. 223.

12. Y.-G. Kim, P.A. Dowben, J.T. Spencer and G.O. Ramseyer. J. Vac. Sci. Technol. A 7 (1989), p. 2796.
13. D. Byun, S. Hwang, P.A. Dowben, K. Perkins, F. Filips and N.J. Janno. Appl. Phys. Lett. 64 (1994), p. 1968.

14. S.-D. Hwang, D. Byun, N.J. Janno, P.A. Dowben and H.R. Kim. Appl. Phys. Lett. 68 (1996), pp. 1495-1497.

15. S.-D. Hwang, N.B. Remmes, P.A. Dowben and D.N. McIlroy. J. Vac. Sci. Technol. B 14 (1996), pp. 2957-2960.

16. S.-D. Hwang, K. Yang, P.A. Dowben, A.A. Ahmad, N.J. Janno, J.Z. Li, J.Y. Lin, H.X. Jiang and D.N. Mcllroy. Appl. Phys. Lett. 70 (1997), pp. 1028-1030.

17. D.N. McIlroy, S.-D. Hwang, K. Yang, N. Remmes, P.A. Dowben, A.A. Ahmad, N.J. Janno, J.Z. Li, J.Y. Lin and H.X. Jiang. Appl. Phys. A 67 (1998), pp. 335-342.

18. B.W. Robertson, S. Adenwalla, A. Harken, P. Welsch, J.I. Brand, P.A. Dowben and J.P. Claassen. Appl. Phys. Lett. 80 (2002), pp. 3644-3646.

19. H. Zeng, D. Byun, J. Zhang, G. Vidali, M. Onellion and P.A. Dowben. Surf. Sci. 313 (1994), pp. 239-250.

20. D. Byun, S. Hwang, J. Zhang, H. Zeng, F.K. Perkins, G. Vidali and P.A. Dowben. Jap. J. Appl. Phys. Lett. 34 (1995), pp. L941L944.

21. J. Zhang, D.N. Mcllroy, P.A. Dowben, H. Zeng, G. Vidali, D. Heskett and M. Onellion. J. Phys. Cond. Matt. 7 (1995), pp. 7185-7194.

22. D.N. McIlroy, J. Zhang, P.A. Dowben and D. Heskett. Mat. Sci. Eng. A 217/218 (1996), pp. 64-68.

23. D.N. McIlroy, C. Waldfried, T. McAvoy, J.W. Choi, P.A. Dowben and D. Heskett. Chem. Phys. Lett. 264 (1997), pp. 168-173.

24. J.M. Carpinelli, E.W. Plummer, D. Byun and P.A. Dowben. J. Vac. Sci. Technol. B 13 (1995), pp. 1203-1206.

25. A.P. Hitchcock, A.T. Wen, S. Lee, J.A. Glass, Jr., J.T. Spenser and P.A. Dowben. J. Phys. Chem. 97 (1993), p. 8171.

26. R.H. Victora and L.M. Falicov. Phys. Rev. B 28 (1983), p. 5232.

27. R. Miranda, F. Yndurain, D. Chandesris, J. Lecant and Y. Petroff. Phys. Rev. B 25 (1982), p. 527.

28. R. Miranda, F. Yndurain, D. Chandesris, J. Lecant and Y. Petroff. Surf. Sci. 117 (1982), p. 319.

29. F.J. Himpsel. Phys. Rev. B 43 (1983), p. 13394.

30. D. Briggs. In: D.R. Clarke, S. Suresh and I.M. Ward, Editors, Surface Analysis of Polymers by XPS and Static SIMS, Cambridge Solid State Science Series, Cambridge University Press (1998).

31. Handbook of X-ray Photoelectron Spectroscopy, Perkin Elmer Corp., Physical Electronics Division, 1992, p. 82-83. 